\title{
OVER-THE-COUNTER ABORTION PILL AND ITS IMPACT ON MATERNAL HEALTH
}

\author{
Uma Mohanraj', Udaya Aruna Sundaram²
}

1Professor, Department of Obstetrics and Gynaecology, KAPV Government Medical College, Trichy, Tamilnadu. ${ }^{2}$ Assistant Professor, Department of Obstetrics and Gynaecology, KAPV Government Medical College, Trichy, Tamilnadu.

\section{ABSTRACT}

\section{BACKGROUND}

Outpatient medical abortion is an acceptable alternative to surgical pregnancy termination in appropriately selected pregnant women less than 49 days' menstrual age. Throughout history, many natural substances have been given for alleged abortifacient effect. In many of these; serious illness and even death have resulted. Currently, there are only 3 medications for early medical abortion that have been widely studied. These are used either alone or in combination and include

- The antiprogestin mifepristone.

- The antimetabolite methotrexate.

- The prostaglandin misoprostol.

Objective- This study was carried out to see the maternal consequences and complications including maternal morbidity and mortality following indiscriminate self-intake of abortion pills reporting in a tertiary medical college hospital.

\section{MATERIALS AND METHODS}

This is a retrospective study carried out at KAPV Govt. Medical College, MGMGH Hospital at Trichy from January 2014 to December 2015. 100 women reported at tertiary institution were studied with respect to the age of the patient, parity, period of gestation, clinical presentation at admission, USG findings, complications and its management. An analysis is made regarding surgical procedures, need of blood transfusion and number of maternal deaths.

\section{RESULTS}

In my retrospective study at KAPV Govt. Medical College, MGMGH, Trichy, there were 67 patients (67\%) presented with profuse bleeding PV, 10 patients (10\%) with acute pain abdomen, 13 patients (13\%) USG reports as retained products, 6 patients (6\%) with infection. Shock was observed in 2 patients (2\%) and 2 patients (2\%) were observed with ruptured ectopic pregnancy. Incomplete abortion is the main complication seen in 76 patients (76.8\%) while complete abortion was in 8 patients (8\%), missed abortion was seen in 9 patients (9\%) and live gestation in 4 patients (4\%). 65 cases received more than one blood transfusion. Maternal death was found in one case in my study.

\section{CONCLUSION}

This study reveals a requirement of immediate and stern action for regulation and total restriction of abortion pills available as over-the-counter without medical prescription. As accessibility to safe abortion service by qualified providers is utmost important to avoid the complications, easy availability in the public and private health facilities is to be insisted to the target people. This helps the service providers to take into account the factors like the woman's personal circumstances and situation and provide respectful, confidential and high quality services.

\section{KEYWORDS}

Mifepristone, Misoprostol, Illegal Usage, Consequences.

HOW TO CITE THIS ARTICLE: Mohanraj U, Sundaram UA. Over-the-counter abortion pill and its impact on maternal health. J. Evolution Med. Dent. Sci. 2017;6(35):2888-2892, DOI: 10.14260/Jemds/2017/623

\section{BACKGROUND}

Outpatient medical abortion is an acceptable alternative to surgical pregnancy termination in appropriately selected pregnant women less than 49 days' menstrual age. Throughout history, many natural substances have been given for alleged abortifacient effect. In many of these; serious illness and even death have resulted.

Financial or Other, Competing Interest: None.

Submission 27-03-2017, Peer Review 20-04-2017,

Acceptance 26-04-2017, Published 01-05-2017.

Corresponding Author:

Dr. Uma Mohanraj,

\#13, Seshapuram, Tennur,

Trichy-17.

E-mail: armohanraj87@gmail.com

DOI: $10.14260 /$ jemds $/ 2017 / 623$
Currently, there are only 3 medications for early medical abortion that have been widely studied. These are used either alone or in combination and include-

- The antiprogestin mifepristone.

- The antimetabolite methotrexate.

- The prostaglandin misoprostol.

Mifepristone and methotrexate increase uterine contractility by reversing progesterone induced inhibition, whereas misoprostol directly stimulates the myometrium. Clark and associates (2006) have reported that mifepristone causes cervical collagen degradation, possibly from increased expression of matrix metalloprotease-2 (MMP-2). Methotrexate and misoprostol are both teratogens. Thus, there must be a commitment to completing the abortion once these drugs have been given.

Abortion is defined as wilful pregnancy termination before the period of viability.(1) The MTP Act enacted in 1971 
governs the provision of abortion or MTP in India. This act allows the termination of pregnancy up to 20 weeks for a broad range of indication. The MTP Act also offers protection to the practitioner if he/she adheres to and fulfils all requirements under the MTP act. The act was amended in December 2002 and the rules in June 2003. The consent of the woman whose pregnancy is being terminated is to be obtained in Form C.

MMA (Medical methods of Abortion)- In case of termination of early pregnancy up to 7 weeks using mifepristone(RU486) and Misoprostol, the registered medical practitioner as defined by the MTP Act, can prescribe the drugs at his/her clinic provided he/she has access to a place approved for terminating pregnancy under MTP Act.(2)

Care should be taken that women with complications of abortion are sensitively attended to, at the facility available without any prejudice.

Mifepristone + misoprostol ( 1 tab of mifepristone $200 \mathrm{mg}$ and $4 \mathrm{tab}$ of misoprostol $200 \mathrm{mcg}$ ) combipack has been approved by the Central Drugs Standard Control Organisation, Directorate General of Health Services for MTP for up to 49 days of LMP in December 2008.(3)

If there is any doubt about the period of gestation based on history or examination by the medical officer at the level of a $24^{*} 7 \mathrm{PHC}$, the woman should be referred to a gynaecologist at FRU for evaluation.

The medical method of abortion carries a very high success rate of $95-98 \%$ if used judicially, as long as the contraindications are not disregarded(4,5) (such as confirmed/suspected ectopic pregnancy, undiagnosed abdominal pain, severe anaemia, uncontrolled hypertension, CVS diseases such as angina, arrhythmia, valvular disease, coagulopathy, allergy/intolerance to mifepristone/misoprostol/other prostaglandins) and psychosocial situation unsuitable for MMA such as-

1. Woman unable to adhere to the protocol due to social and personal reasons.

2. Woman who want quick abortion.

3. Language and comprehension barrier.

Despite this recommendation, it has been looked by the society that medical abortions are extremely safe even in the hands of untrained health professionals leading to over-thecounter purchase and increase in the unwanted pregnancy termination, unsupervised culminating in life threatening complication and even mortality. As ours being a tertiary care institution, many cases of self-medication of abortion pills lead to referral in a late morbid state here.

\section{MATERIALS AND METHODS}

This is a retrospective study undertaken in a tertiary institute KAPV Govt. Medical College and Mahatma Gandhi Memorial Hospital, Trichy between January 2014 and December 2015 for a period of 2 years. A study of 100 women who are reported to our hospital following self-consumption of MTP pills purchased over-the-counter by self/husband/family member without any eligibility like provider's eligibility, site eligibility, indication, contraindication and any special precaution. This study elicited the age of the patient, parity, gestational age, presenting clinical features at the time of admission. The patients on admission are examined for detailed general, systemic, obstetric examination including obstetric USG examination. The features of shock, severity of pallor, body temperature recording, presence of acute abdominal pain were noted. The management of complication such as surgical evacuation, need for blood transfusion, treatment of sepsis and maternal death if any were noted.

\section{The Statistical Methods used to evaluate the data were-}

1. The frequency distribution curve method.

2. Crosstabs procedure method.

\section{RESULTS}

An observational study of 100 cases were studied. The data obtained from our study is detailed below.

\begin{tabular}{|c|c|c|}
\hline Age in Yrs. & Number & Percentage \\
\hline$<20$ & 5 & 5 \\
\hline $21-25$ & 20 & 20 \\
\hline $26-30$ & 42 & 42 \\
\hline $31-35$ & 26 & 26 \\
\hline$>36$ & 7 & 7 \\
\hline \multicolumn{3}{|c|}{ Table 1 } \\
\hline
\end{tabular}

The self-usage of abortion pill is more common in age group 26-30 which contributes for about $42 \%$, nearly $26 \%$ of the patients were within 31- 35 years, age less than 25 yrs. contribute $1 / 3$ of the cases and age $>35$ yrs. contributes $7 \%$.

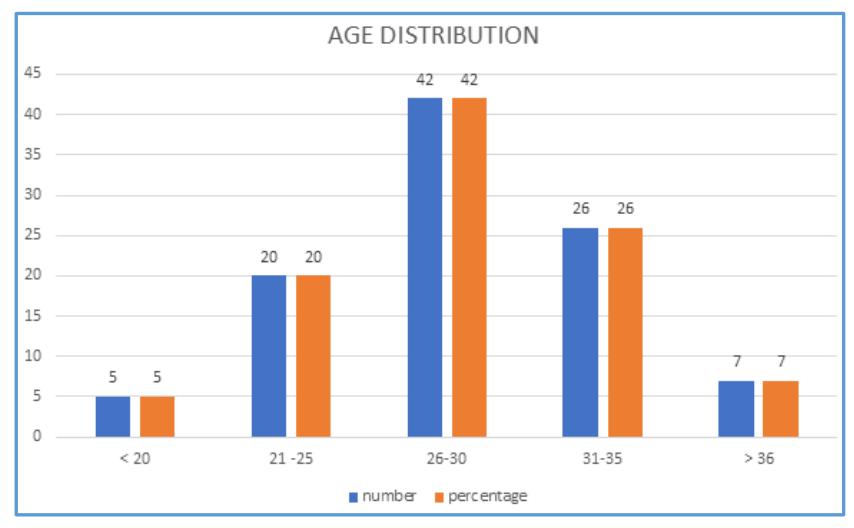

Figure 1

\begin{tabular}{|c|c|c|}
\hline Parity & Number & Percentage \\
\hline Primi & 12 & 12 \\
\hline Gravida 2 & 16 & 16 \\
\hline Gravida 3 & 37 & 37 \\
\hline > Gravida 3 & 35 & 35 \\
\hline \multicolumn{3}{|c|}{ Table 2 } \\
\hline
\end{tabular}

In my study, the self-intake of abortion pill is more common with parity of 3 or more which contributes to about $35 \%$; for women with 3 children, 37 patients have undergone abortion and patient with obstetric score of 2 children were 16 patients and in primi $12 \%$ have undergone MMA. 


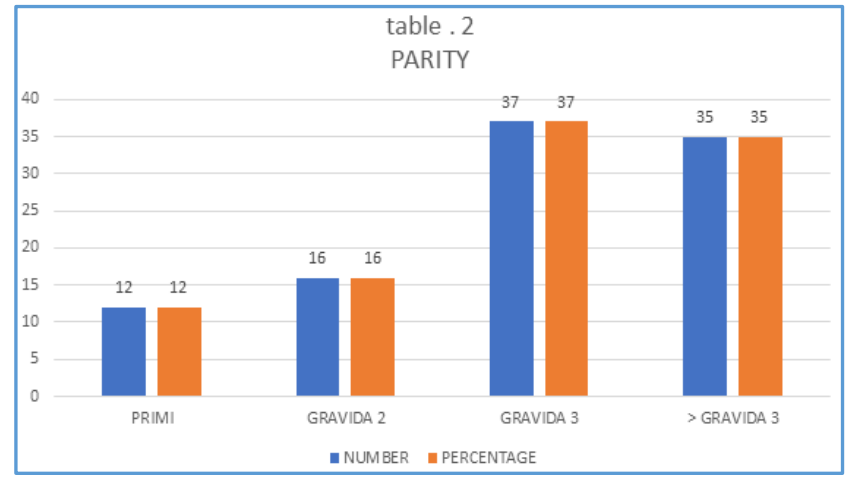

Figure 2

\begin{tabular}{|c|c|c|}
\hline Gestational Age & Number & Percentage \\
\hline Before 7 weeks & 32 & 32 \\
\hline 7-10 weeks & 37 & 37 \\
\hline >10 weeks & 31 & 31 \\
\hline \multicolumn{3}{|c|}{ Table 3 } \\
\hline
\end{tabular}

The observations in my study are patients with gestational age $<7$ weeks were $32 \%$ and from 7-10 weeks were $37 \%$ and $31 \%$ of patients contributed for gestational age $>10$ weeks.

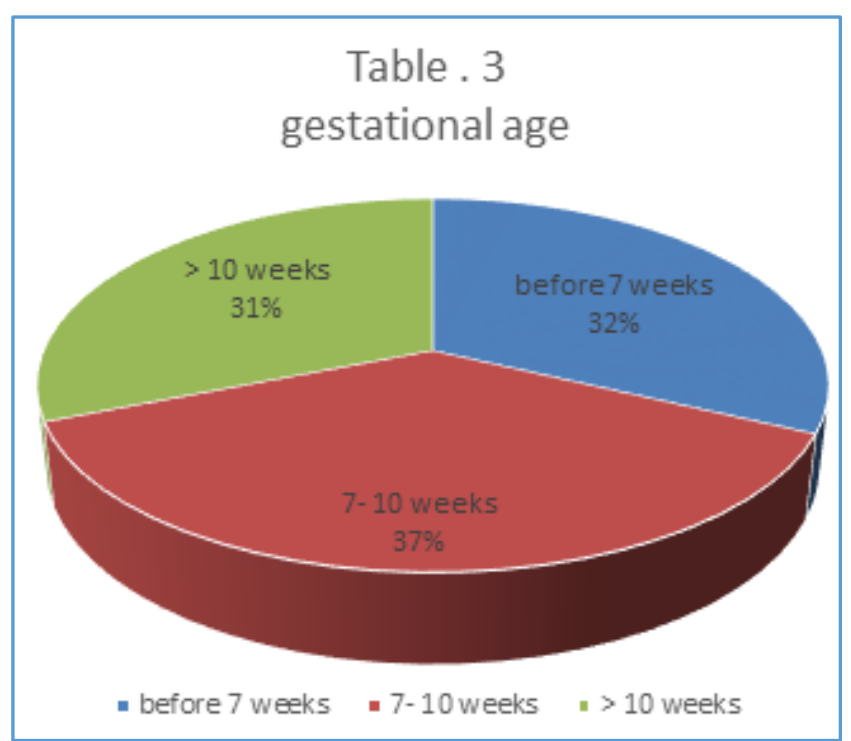

Figure 3

\begin{tabular}{|c|c|c|}
\hline Presentation & Number & Percentage \\
\hline Bleeding PV & 67 & 67 \\
\hline Pain abdomen & 10 & 10 \\
\hline USG -retained products & 13 & 13 \\
\hline Infection & 6 & 6 \\
\hline Shock & 2 & 2 \\
\hline Ruptured ectopic & 2 & 2 \\
\hline \multicolumn{2}{|c|}{ Table 4. Clinical Presentation on Admission } \\
\hline
\end{tabular}

In my study, nearly $67 \%$ of the patients presented with bleeding PV, $10 \%$ with pain abdomen, $13 \%$ with USG reports showing retained products, $6 \%$ with infection. $2 \%$ presented with shock and $2 \%$ with ruptured ectopic.

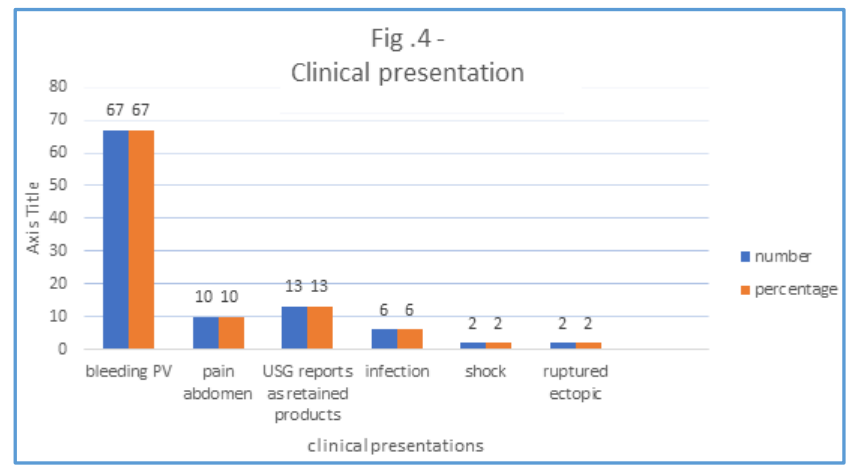

Figure 4

\begin{tabular}{|c|c|c|}
\hline USG Findings & Number & Findings \\
\hline Incomplete abortions & 76 & 76 \\
\hline Complete abortions & 8 & 8 \\
\hline Missed abortions & 9 & 9 \\
\hline Live gestations & 4 & 4 \\
\hline Ruptured ectopic & 2 & 2 \\
\hline Table 5. USG Findings at the Time of Admission \\
\hline
\end{tabular}

Ultrasonography done showed incomplete abortion is $76 \%$ of the study group, complete abortion is $8 \%, 9$ patients presented with missed abortions, $2 \%$ with ruptured ectopic and $4 \%$ with live gestation.

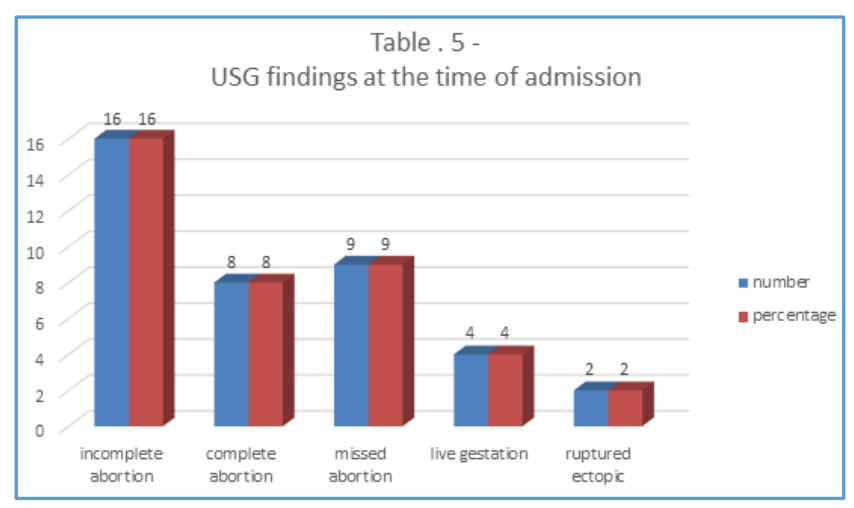

Figure 5

\begin{tabular}{|c|c|c|}
\hline Complication & Number & Percentage \\
\hline Anaemia & 77 & 85.6 \\
\hline Sepsis & 9 & 10 \\
\hline Ruptured ectopic & 2 & 2.2 \\
\hline Rupture uterus & 2 & 2.2 \\
\hline \multicolumn{2}{|c|}{ Table 6. Complications } \\
\hline
\end{tabular}

The complications are- nearly 77 patients presented with anaemia; of the rest, $10 \%$ developed sepsis, 2 patients had ruptured uterus, 2 patients had ruptured ectopic. 


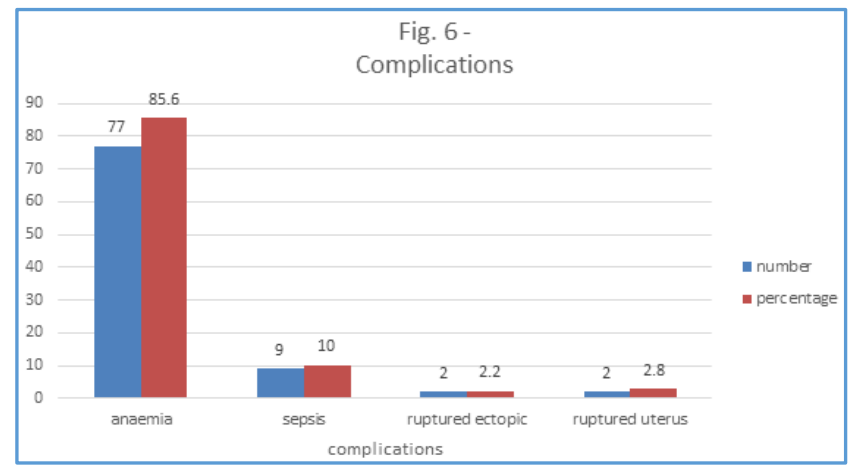

Figure 6

\begin{tabular}{|c|c|}
\hline Number of Transfusion & Number of Patients \\
\hline 0 & 5 \\
\hline One & 30 \\
\hline > one & 65 \\
\hline \multicolumn{2}{|c|}{ Table 7. Requirement of Blood Transfusion } \\
\hline
\end{tabular}

Requirement of blood transfusions - 65 patients in our study group required more than one blood transfusion and 30 patients were in need for 1 transfusion and 5 patients had no transfusion.

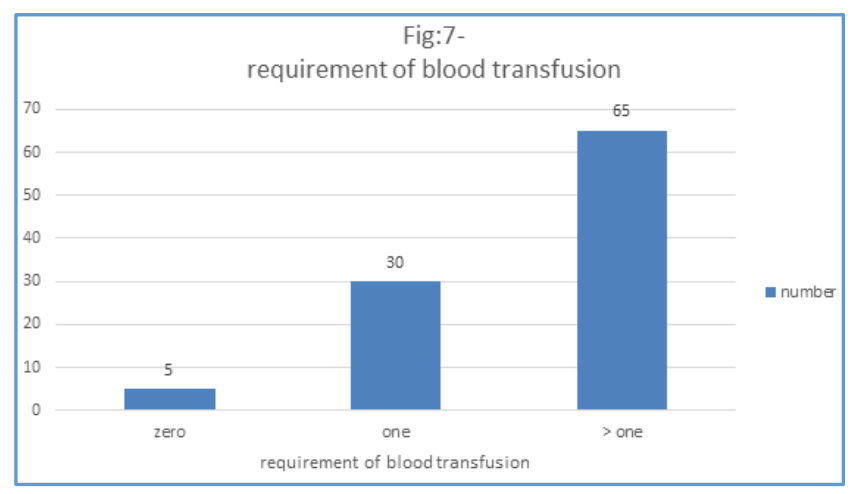

Figure 7

\section{DISCUSSION}

While guidelines pertaining to different components of abortion case are in existence, there is a strong felt need among service providers and health managers for updated and comprehensive guidelines on medical termination of pregnancy (MTP). The Ministry of Health and Family Welfare's Comprehensive Abortion Care (CAC) Training and service delivery guidelines have been developed in response to this need. The guidelines have been developed to provide health workers with stipulations and guidance for reference during service delivery, improving service quality as well as to provide health administrators with standards to evaluate quality of care as well as checklists for monitoring and supervision.

While retaining the clinical perspective, these guidelines are more comprehensive and woman centric. This helps service providers to consider factors like the woman's personal circumstances and situation and provide respectful, confidential and high quality service.

As per the guidelines, MMA - in case of termination of early pregnancy up to 7 weeks using Mifepristone (RU486) and misoprostol, the registered medical practitioner, as defined by the as defined by the MTP Act, can prescribe the drugs at his/her clinic provided he/she has access to a place approved for terminating pregnancy under the MTP Act.(3)

Mechanism of action: Mifepristone is a derivative of norethindrone with antiprogestin action. It binds to progesterone receptors in the endometrium and decidua resulting in the necrosis and detachment of products of conception. It also softens the cervix and causes mild uterine contractions. Mifepristone sensitises uterus to the effect of prostaglandins.

Misoprostol is a prostaglandin which binds to myometrial cells causing strong myometrial contractions and causes cervical softening and dilatation. This leads to expulsion of the conceptus from the uterus. It is stable at room temperature and well absorbed from gastrointestinal tract and vaginal mucosa. Being selective for PGE1 receptors, there are no significant effects on the bronchial and blood vessels, minimising its side effects when compared to other prostaglandins. Provider's eligibility: any provider who is recognised by the MTP Act as a registered medical practitioner entitled to terminate a first trimester pregnancy can use MMA to perform the procedure. Site eligibility: primary, secondary and tertiary level of public health care sites.

Private sector facilities, which have been approved by the government as certified MTP sites.

Outpatient facilities (Clinics) which are not approved as MTP certified sites but have an established referral linkage to a MTP certified site and the clinic displays a certificate to the effect by the owner of the certified site.

\section{Indications}

- Willing to make minimum of three visits.

- Able to understand the instructions completely.

- Ready for surgical evacuation in case of failure of the method of excessive bleeding.

- Within accessible limits of the appropriate health data.

\section{Contraindications}

- Confirmed or suspected ectopic pregnancy or undiagnosed adnexal mass, as mifepristone is not an effective treatment for ectopic pregnancy.

- Anaemia (hb-<8 g\%).

- Uncontrolled hypertension with BP >160/100 mmHg.

- Cardiovascular diseases such as angina, valvular disease, arrhythmia.

- Coagulopathy or women on anticoagulant therapy.

- Chronic adrenal failure or current long term use of systemic corticosteroids.

- Allergy or intolerance to mifepristone/misoprostol or other prostaglandins.

- Severe renal, liver or respiratory diseases or uncontrolled seizure disorder.

\section{Special Precautions}

- Pregnancy with uterine scar: up to 9 weeks of pregnancy, MMA is safe in woman with scarred uterus.

- Pregnancy with in situ intrauterine device (IUD): IUD has to be removed before giving drugs for abortion.

- Severe pelvic infection and sepsis.

- Bronchial asthma. Misoprostol is a weak bronchodilator and therefore could be used in women with bronchial asthma; however, prostaglandins other than misoprostol should not be used. 
- Use of antitubercular drugs - these may decrease the efficacy of medical abortion drugs.

After a special precaution, it is a must to have a general counselling on abortion, Pre-abortion counselling before the medical pills, number of visits to the doctor, Family support and health care facility at accessible limits, side effects of the drugs, need for surgical evacuation in case of failure or excessive bleeding and role of congenital malformation in case of continuation of pregnancy.

Clinical assessment before the procedure and the investigation required are same as for other techniques for pregnancy termination.

\section{Role of Ultrasonography}

It is not mandatory to perform an ultrasonography for all women undergoing termination of pregnancy with medical methods. USG is indicated for-

- Women unsure of LMP or who have conceived during lactational amenorrhea.

- Women having irregular cycles.

- Women with discrepancy between history and clinical findings.

- Women with suspicion of ectopic pregnancy.

- Provider uncertainty with exam, or inability to measure uterine size due to obesity, pelvic discomfort, or an uncooperative woman.

The women in the retrospective study, procured the pills over-the-counter without the health professional prescription, the need of medical supervision and adherence to the recommended drug schedule and follow-up visits is unaware to the patients.

In my observational study, 8\% women were unmarried and $72 \%$ women were gravida 3 and more, $68 \%$ of women were under the age group 26-30 \& 31-35 years. Both these data imply that the self-usage of abortion pill is to get rid of unwanted pregnancy. This shows the need of strengthening of current available abortion case services to improve the overall quality of health care. In our study, only $32 \%$ had taken pills before 7 weeks of pregnancy which is the recommended schedule for medical abortion. The women of $68 \%$ had consumed pills beyond the recommended period, beyond 7 weeks of gestation.

My study in this respect substantiates the findings as per Thacker et $\mathrm{al}^{(6)}$ from that when there is a self-intake of abortion pill, the women are unaware of the gestational age when to take and totally unaware of possibilities of serious life threatening emergencies like profuse bleeding PV, Sepsis, shock, ectopic pregnancy and maternal death.

On USG examination, only $8 \%$ had complete abortion and the rest $76 \%$ had incomplete abortion similar to Thacker et $\mathrm{al}^{(6)}$ studies and Bajwa et al studies. There were 2 cases of ruptured ectopic; both underwent laparotomy and partial salpingectomy with more than 2 units of blood transfusion. Similar results about the incidence of ectopic pregnancy are found in Bajwa study \& in study conducted by Debnath et al.(7)
In our study, $10 \%$ were found with sepsis, treated with higher antibiotics and blood transfusions.

In our observational study, there was one maternal death, she was a case of G4P3L3 with severe anaemia with 10 weeks of gestation. Self-consumed abortion pill in a rural setup, to avoid the unwanted pregnancy reported to us, in a late stage with incomplete abortion with $\mathrm{Hb}-3 \mathrm{~g}$, irreversible haemorrhagic shock. Patient died within 2 hours of admission.

\section{CONCLUSION}

This study reveals a requirement of immediate and stern action for regulation and total restriction of abortion pills available as over-the-counter without medical prescription. As accessibility to safe abortion service by qualified providers is utmost important to avoid the complications, easy availability in the public and private health facilities is to be insisted to the target people. This helps the service providers to consider factors like the woman's personal circumstances and situation and provide respectful, confidential and high quality services.

It is important to facilitate access to comprehensive abortion care for all women with the planning and provision of safe abortion services taking place within a woman centred care model. This recognises and respects the rights of women to control their reproductive lives.

Availability of a safe, effective and acceptable abortion care services is one of the most important aspects of women's reproductive health. The need of the hour was the guidelines on abortion services, key elements of counselling, contraception that are required to provide women with the highest quality of care.

\section{REFERENCES}

[1] Cunningham FG, Leveno KJ, Bloom SL, et al. Abortion, Williams Textbook of obstetrics. 24th edn. New York: McGraw Hill 2014:215-35.

[2] International consensus conference on nonsurgical (medical) abortion in early first trimester on issues related to regimen and service delivery. Frequently asked clinical question $\mathrm{s}$ about medical abortion, Geneva, WHO 2006:159484-5.

[3] Ellertson C, Waldman SN. The mifepristonemisoprostol regimen for early medical abortion. Curr women health Rep 2001;1(3):184-90.

[4] Kapur K, Joneja GS, Biswas M. Medical abortion-an alternative to surgical abortion. MJAFI 2006;62(4):351-3.

[5] Coyaji K. Early medical abortion in India: three studies and their implications for abortion services. J Am Med women assc 2000;55(3 Suppl):191-4.

[6] Thaker RV, Deliwala KJ, Shah PT. Self-medication of abortion pills: women health in jeopardy. NHL J Med science 2014;3(1):26-31.

[7] Sonali D, Kanan Y, Ajit D, et al. Competitive study of medical abortion by mifepristone with vaginal misoprostol in in women $<49$ days versus 50-63 days of amenorrhea. J obst And gynaec india 2010;60(5):403-7. 